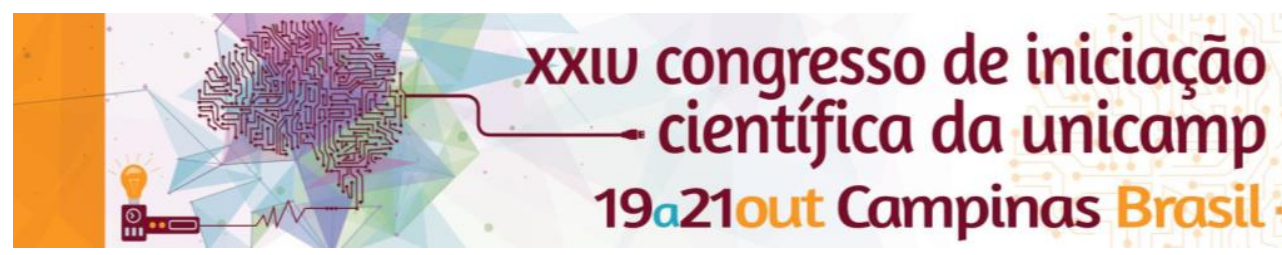

\title{
Interação tri-trófica entre Ipomoea cairica (Convolvulaceae), besouros da subfamília Bruchinae (Coleoptera: Chrysomelidae) e seus parasitoides associados.
}

\section{Beatriz H. B. Affonso*, João Vasconcellos Neto.}

\section{Resumo}

Mais do que sua aplicação no manejo de pragas, as interações tri-tróficas são componentes essenciais para o entendimento dos padrões de coexistência e diversidade. Nelas, os inimigos naturais estão entre os principais fatores limitantes do crescimento populacional. No presente estudo, parasitoides apresentaram alta taxa de parasitismo em bruquíneos hospedes de I. cairica, sugerindo que o controle dos besouros nesse sistema se dá de forma top-down.

\section{Palavras-chave:}

Interação tri-trófica, Convolvulaceae, Bruchinae

\section{Introdução}

Frente à pressão seletiva exercida por insetos herbívoros, plantas desenvolveram diversos mecanismos de defesa intrínsecos (físicos e químicos). Por sua vez, os insetos desenvolveram respostas a essas defesas, em um processo contínuo de interação e evolução recíproca, conhecido como coevolução. Plantas desenvolveram ainda mecanismos extrínsecos de defesa, atraindo, de diversas formas, predadores e/ou parasitoides dos herbívoros. Esses inimigos naturais de terceiro nível trófico controlam as populações de consumidores primários, permitindo o desenvolvimento do produtor ${ }^{1}$. Neste trabalho investigamos a interação tri-trófica entre Ipomoea cairica, coleópteros predadores de semente da subfamília Bruchinae e seus parasitoides, por meio do estudo de uma série temporal de um ano, usando plantas de áreas ruderais do Campus da Universidade Estadual de Campinas, em Barão Geraldo.

\section{Resultados e Discussão}

A fenologia da planta $(\mathrm{N}=20)$ foi registrada todos os meses. A porção vegetativa (folhas) esteve presentes de forma constante ao longo do ano, indicando que esta é uma espécie perene. Ela também floresce e produz frutos o ano todo, havendo, no entanto, um pico de floração e frutificação no outono e inverno, períodos em que houve menor quantidade de chuva total (fig. 1) e também temperaturas médias mais baixas.

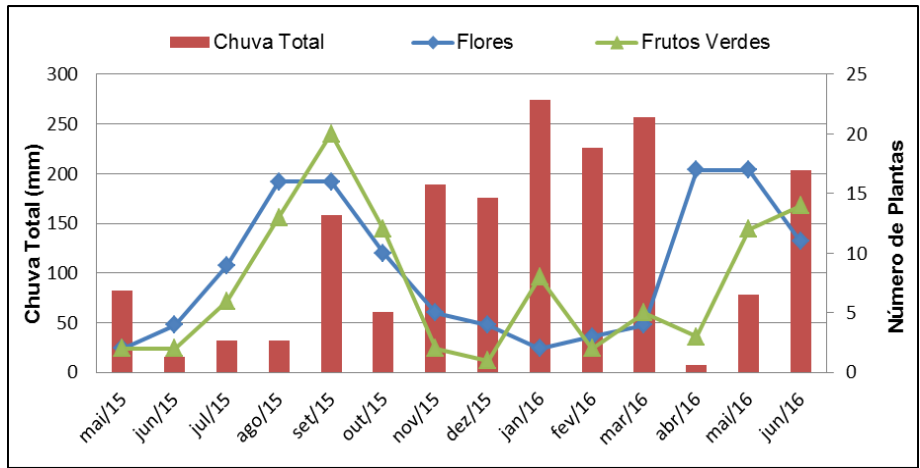

Figura 1. Gráfico mostrando a chuva total e o número de plantas (dentre as 20 totais mensais) registradas com flores e frutos verdes na fenologia de cada mês.

Foram coletados mensalmente 100 frutos secos, que foram individualizados em recipientes plásticos e mantidos secos e em temperatura ambiente durante três meses, tempo necessário para emergirem os besouros e parasitoides adultos. Foram obtidos no total 43 besouros e 395 parasitoides da ordem Hymenoptera. Os bruquíneos foram identificados como pertencentes ao gênero Megacerus e emergiram em maior abundância na primavera e início de verão (fig. 2), indicando uma defasagem temporal em relação ao pico de frutos verdes de cerca de dois meses. A taxa media de ataque dos frutos por esses besouros foi de $6,5 \%$, sendo o maior valor de $11 \%$. Além disso, foram encontrados 12 morfotipos de himenópteros associados a esse sistema, dos quais cinco parecem estar intimamente relacionados com o besouro e que foram identificados como pertencentes às famílias Eulophidae, Scelionidae e Pteromalidae. A taxa média de parasitismo foi de $42 \%$, variando de zero a $67 \%$.

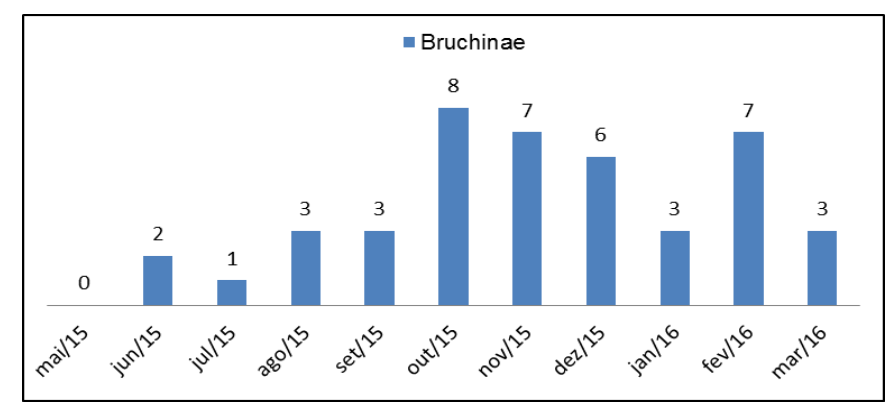

Figura 2. Número de indivíduos bruquíneos adultos emergidos em cada mês.

\section{Conclusões}

Para análises mais robustas das interações tri-tróficas desse sistema em termos temporais, há a necessidade de ampliar os dados por pelo menos mais um ano. Considerando a alta taxa de parasitismo encontrada e um valor menor de taxa de ataque aos frutos, o controle da população do herbívoro parece de fato ser do tipo topdown, onde os parasitoides mantêm a população de besouros em baixos níveis, reduzindo seu impacto como predadores de sementes sobre a planta hospedeira.

CNPq, Unicamp

\section{Agradecimentos}

\footnotetext{
1 Hairston, N.G.; Smith, F.E. e Slobodkin, L. B.. Community structure, population control and competition. American Naturalist. 1960, 94: 421 425.
} 